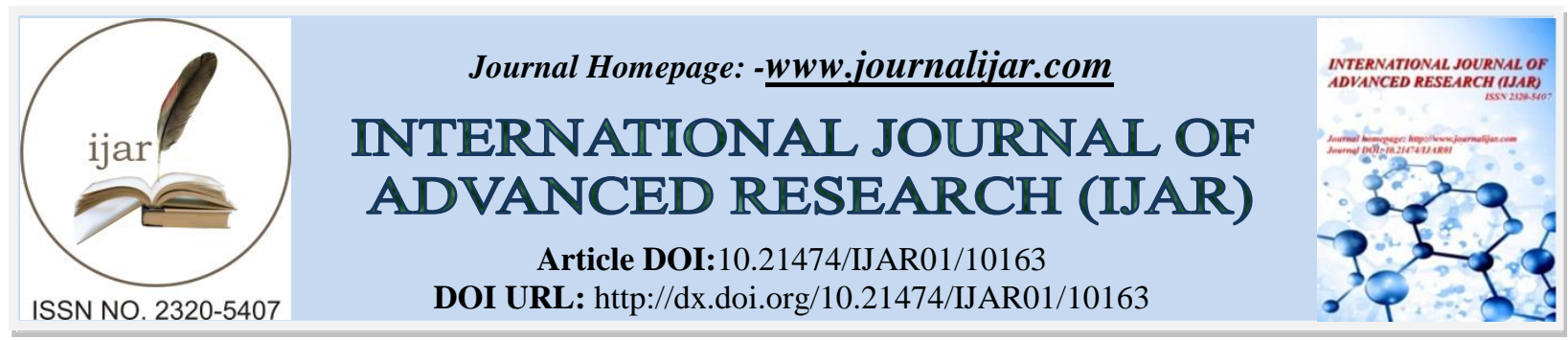

RESEARCH ARTICLE

\title{
COMPARATIVE MICROANATOMY OF ORGANS OF ANENCEPHALIC \& NORMAL FETUSES OF DIFFERENT GESTATIONAL AGE GROUPS.
}

\section{Shilpa $K^{1}$, Sumathi Shekar ${ }^{2}$ and Priya Ranganath ${ }^{3}$.}

1. Assistant professor, Department of anatomy \& neuroscience, Trinity school of medicine, Trinity medical science university, Ratho mill, St Vincent \& Grenadies, West Indies.

2. Associate Professor, Department of anatomy, Bangalore medical college \& research institute, Fort, Bangalore 56002, Karnataka.

3. 3 .Professor \& head, Department of anatomy, Bangalore medical college \& research institute, Fort, Bangalore 56002, Karnataka.

\section{Manuscript Info}

Manuscript History

Received: 03 October 2019

Final Accepted: 05 November 2019

Published: December 2019

Key words:-

Anencephaly, calvaria, Nephrogenic zone.

\section{Abstract}

Background: Anencephaly is Neural tube defect which is a most common birth defects. This was a hospital based case finding study that covered 60 patients with anencephaly \& their respective mothers conducted in hospitals in Bangalore Medical College \& Research Institute from 2014 to 2017.

Methods: The study includes 60 anencephalic fetuses ( 23 males \& 37 females) of 20-30 weeks. The fetuses were examined for external abnormalities \& dissected. Dissected fetal kidney, ureter, stomach, suprarenal gland, thyroid gland, pancreas, lung and liver tissues were processed \& stained with $\mathrm{H} \& \mathrm{E}$.

Results: Histological study of the anencephalic organs were studied, Stomach was normal in all the cases. Ureter in 98\% cases was normal $\&$ in $2 \%$ cases, illformed muscular layer was seen. Only in $2.2 \%$ of cases Suprarenal gland showed rosettes cell tumor which are little rounded grouping of cells found in tumors .Abnormal development of some hepatocytes \& hepatic sinusoids was induced by abnormal development of nervous system of anencephalic fetus which was also found.

Copy Right, IJAR, 2019,. All rights reserved.

\section{Introduction:-}

The central nervous system (CNS) appears at the beginning of the third week as a slipper-shaped plate of thickened ectoderm, the neural plate, in the mid-dorsal region in front of the primitive node. Its lateral edges soon elevate to form the neural folds. With further development, the neural folds continue to elevate, approach each other in the midline, \& finally fuse, forming the neural tube. Fusion begins in cervical region \& proceeds in cephalic \& caudal directions. Once fusion is initiated, the open ends of neural tube form the cranial \& caudal neuropores that communicate with the overlying amniotic cavity.

Closure of cranial neuropores proceeds cranially from the initial closure site in the cervical region \& from a site in the forebrain that forms later. This later site proceeds cranially, to close the rostral-most region of the neural tube, \& caudally to meet advancing closure from the cervical site .Final closure of the cranial neuropores occurs at the 18 to

Corresponding Author:- Shilpa K.

Address:- Assistant professor, Department of anatomy \& neuroscience, Trinity school of medicine, Trinity 372 medical science university, Ratho mill, St Vincent \& Grenadies, West Indies. 
20- somite stage $\left(25^{\text {th }}\right.$ day); closure of the caudal neuropores occurs approximately 3 days later. Occasionally the neural groove fails to close because of faulty induction of surrounding mesodermal structures $\&$ the neural tube then remains exposed to the surface. Such a defect is localized in the cephalic region. Moreover the vault of the skull may be absent, giving the head the characteristic appearance, the eyes bulge forward, the neck is absent $\&$ the surface of the face $\&$ chest form a continuous plane. Anencephaly is a congenital anomaly characterized by gross defects of the head \& often inability to swallow. Hydramnios (amniotic fluid $>21$ itres) is frequently associated with it. ${ }^{(1)}$

The incidence of anencephaly is 1:1000 to 1:20,000 infants. The causes of anencephaly may be chemical, dietary or genetic. Skeletal system, cardiovascular system, central nervous system \& urogenital system may be involved in anencephaly. Several maternal serum tests can be done to diagnose anencephaly at early pregnancy.

Acrania is a condition in which the calvaria is absent (a roofless skull) \& extensive defects of vertebral column are present. There is severe arrest of brain development \& even degenerative regression causing anencephaly. The central hemisphere $\&$ other regions of brain usually suffer such damages. ${ }^{(2)}$

Acrania associated with mero anencephaly or anencephaly (partial absence of brain) occurs in about one in 1000 births \& is incompatible with life. Meroanencephaly results from the failure of cranial end of neural tube to close during the fourth week $\&$ causes subsequent failure of formation of calvaria. ${ }^{(3,4)}$

\section{Associated anomalies:-}

Skeletal system: Severe cases of spina bifida with meningomyelocele involving several vertebrae are often associated with partial absence of brain-Meroanencephaly or anencephaly.

Klippel-feil syndrome (KFS) is a heterogenous entity, characterized by specific congenital anomalies of segmentation of cervical spine.Inanencephaly and anencephaly are probably the extreme manifestations of KFS rather than different dysraphisms.

Cardiovascular system: Anencephalic infants are potential donors in pediatric heart transplantation. So it is important to define any morphologic differences between anencephalic and normal heart in new born.

The dimensions of the heart in the anencephalics may differ. The absence of cerebral tissue in anecephalic foetuses may decrease the heart load resulting in a smaller heart.

The position of heart in the thoracic cavity of an anencephalic foetus may affect size and shape of heart. It is also found that the left ventricular volumes are significantly smaller than right ventricular volume. The outlet length of right ventricle and the inlet and outlet length of left ventricle in anencephalic fetuses are shorter than normal.

Some studies have not found any differences between anencephalic and normal foetuses. ${ }^{7}$ Some studies have seen coarctation of the aorta, persistent truncus arteriosus, pulmonary atresia, single ventricle, and other major septal defects. An additional 2 to 31 percent of infants with anencephaly have other minor developmental abnormalities, such as single umbilical artery, patent ductus arteriosus and patent foramen ovale.

Central Nervous System (Craniofacial): case report showed pseudo-aprosencephaly with severe brain malformation. In a microcephalic premature newborn only a small structure was found in base of cranium corresponding to prosencephalic part of brain. The basal ganglia were lacking in the cortico subcortical area with only small fragments of cortical strip.

Various structures of nervous system including diencephalon and the optic nerves, cerebellum, brain stem and spinal cord may also be malformed, other associated anomalies include diprosopus, lowset ears, flattened nasal bridge, cleft palate, corneal clouding, microophthalmia and exophthalmos occur frequently.

\section{Materials \& Methods:-}

The study design and data collection was a prospective, observational, hospital based study conducted in main hospital of Victoria attached to Bangalore Medical college \&research institute (BMCRI), Bangalore; during the period of Aug 2014 to June 2017.The study includes all the patients born with anencephaly, 60 anencephalic fetuses 
(23 males and 37 females) of 20 -30 weeks and 20 non anencephalic fetuses of age 20 -30 weeks ; which were delivered in the Department of obstetrics \& gynecology, Victoria hospital, Bangalore.

A structural socio demographic questionnaire was designed to capture basic data about gender, age, maternal history like socioeconomic data, environmental history, educational qualification, family history. A detailed proforma was developed for collecting the required details of the mother and the fetus. The patients who met the above criteria were selected. Approval was obtained from the Institutional Ethics Committee of Bangalore Medical College \& Research Institute prior to data collection. Informed consent as per 'The Indian Council of Medical Research' guidelines was obtained from the participants before data collection.

Fetuses were cavity embalmed with $10 \%$ formalin and then dissected. The fluid strength was determined by the condition of the body. As infant body tissue contains higher percentage of water than adult body tissue, adult $10 \%$ formalin was used but volume of fluid was reduced than adults; it depended upon size and weight of the body.

A curved incision was made bilaterally from the acromion process through the medial border of shoulder joint to mid-axillary line laterally, this continued to the iliac crest over the inguinal ligament to meet pubic symphysis. The skin with the superficial tissue flap was reflected up the root of the neck, then to the inferior margin of mandible bilaterally, taking care not to injure the neck structures and rectus sheath. This way, whole of the front of the neck, chest and abdomen was exposed. ${ }^{(10)}$

\section{Opening abdominal cavity:-}

A paramedian incision was made on rectus near pubic symphysis upto xiphoid process.

\section{Opening thoracic cavity:-}

Sternum was removed by cutting at costochondral junction and then separating sternoclavicular joint.

The position, external features and any anomalies of each organ was observed

Dissected tissues of kidney, ureter, stomach, suprarenal gland, thyroid gland, pancreas, lung and liver of anencephalic fetuses and non anencephalic fetuses were fixed for 24 hours and then tissue processing was performed.

The staining was done by $\mathrm{H} \& \mathrm{E}$ technique. Slides were checked under (10x) low power and then under high power (20x, 40x, 100x ie oil immersion), identified, analyzed, photographed and then reported using Olympus BX51 polarized microscope with inbuilt camera.

\section{Following are checklist of cell layers of organs:}

\begin{tabular}{|l|}
\hline 1.Kidney \\
Nephrogenic zone (last formed nephrons) \\
Gortex \\
Bowman'us \\
Tubules \\
Blood vessels \\
Medulla \\
Collecting ducts \\
\hline 2.Ureter \\
Mucosa \\
Transitional epithelium \\
Star shaped fold \\
Muscle layer \\
Adventitia \\
\hline 3.Stomach \\
Mucosa \\
Simple columnar epithelium \\
\hline
\end{tabular}




\begin{tabular}{l} 
Pits \\
Lamina propria \\
Muscularis mucosa \\
Submucosa \\
Serosa \\
\hline 4.Pancreas \\
Capsule \\
Lobules \\
Acini \\
Intra \& interlobular ducts \\
Islets of Langerhans \\
5.Lung \\
Conducting part \\
Intrapulmonary bronchus \\
Terminal bronchiole (simple columnar epithelium) \\
Respiratory bronchiole (simple columnar epithelium) \\
Alveolar duct \\
Alveoli \\
Blood vessels
\end{tabular}

6.Liver

Hepatic lobule (ill defined)

Portal vein

Portal triad

Hepatocytes

Hepatic sinusoid (any congestions)

Hemopoietic cells

Capsule

Extramedullary Hepatocytes

Bile in hepatocytes

7. Thyroid gland

Thyroid follicles

Colloid Parafollicular cells

Blood capillaries

8. Suprarenal gland Definite fetal cortex

Zona glomerulosa

Zona fasciculata

Zona reticularis

Chromaffin cells in medulla

Simple descriptive statistics were performed on Statistical Package for Social sciences (SPSS) software version17. Level of significance was set on an alpha level at 0.05 .

\section{Results:-}

In this prospective study 60 anencephalic fetuses (23 males and 37 females) of 20-30 weeks and 20 non anencephalic fetuses of age 20 -30 weeks; which were delivered in the Department of obstetrics \& gynecology, Victoria hospital, Bangalore during the period of Aug 2014 to June 2017.

Age of the fetuses were taken as main consideration because few organs are not completely developed up to 25 weeks to analyze the histological features hence it is classified into 2 groups:

1. Group1 includes $20-25$ weeks.

2. Group 2 is $26-30$ weeks. 
In control group (20 normal fetuses).

\section{Group 1-}

includes 10 fetuses \& Group2 -includes 10 fetuses.

Histological features of Control group of kidney, ureter, stomach, suprarenal gland, thyroid gland \& pancreas all the cell layers were present in $100 \%$ of fetuses. Liver lobular pattern was not well developed. In lungs, Group 1 of control group showed alveoli, alveolar ducts were not well developed, whereas in Group 2 all the layers were normal.

Histological features of Test group (60 anencephalic fetal organs).

Kidneys-

Group 1-

$13.3 \%$ cases had ill formed nephrogenic zone, $2.2 \%$ cases glomeruli was absent, ill formed nephrogenic zone \& medulla is deviated \& $84.4 \%$ were normal.(Fig $1 \mathrm{~A})$

\section{Group 2-}

$73.3 \%$ cases were normal; only in $26.6 \%$ cases ill formed nephrogenic zone was seen.(Fig 1B)

Ureter of anencephalic fetus were normal, expect in $2.2 \%$ of cases only had ill formed muscular layer.

Stomach in $100 \%$ of anencephalic fetuses all the layers were normal. (Fig 2)

\section{Liver -In Group 1-}

$28.8 \%$ \& in Group $213.3 \%$ of liver showed that portal triad, vein, hepatocytes were not well developed. $71.2 \%$ of Group 1 were normal \& it was found to be statistically significant (fig 3)

\section{Pancreas-In Group 1-}

$13.3 \%$ cases absence of islets of Langerhans \& $86.7 \%$ cases normal (fig 4 ).

\section{Group2-}

$4.7 \%$ cases absence of islets of Langerhans \& $95.3 \%$ cases were normal.

\section{Lung -}

Group 1-

95.5\% Alveoli, alveolar ducts, respiratory bronchiole were not well developed, this is a normal feature of this group because age group of fetuses is $20-25$ weeks \& in $4.4 \%$ of cases the alveoli was collapsed. (Fig 5A \&B)

\section{Group 2-}

$66.7 \%$ cases were normal, $33.3 \%$ cases alveoli, alveolar ducts were not well developed.

\section{Thyroid gland of Group 1-}

$22.2 \%$ cases ill formed follicles \& it was statistically significant (fig 6).

Only in $2.2 \%$ of cases Suprarenal gland showed rosettes cell tumor which are little rounded grouping of cells found in tumors. (They usually consist of spoke wheel like arrangement surrounding a central, acellular region, which is the most common tumor cells which was seen in below 2 year infants (? neuroblastoma)( fig 7)

\section{Discussion:-}

The study conducted in main hospitals of Bangalore with main objective of histological variation of cerebrum $\&$ cerebellum in anencephalic \& non anencephalic fetuses. Incidence of anencephaly is reported to be 1:1000 to 1:20000. In the present study the incidence of anencephaly in Victoria and Vanivilas hospital was 1.04 in 1000 births.

Histological study of the anencephalic organs were studied, Stomach was normal in all the cases. Ureter in $98 \%$ cases was normal \& in $2 \%$ cases, illformed muscular layer was seen. Only in $2.2 \%$ of cases Suprarenal gland showed rosettes cell tumor which are little rounded grouping of cells found in tumors .Abnormal development of 
some hepatocytes \& hepatic sinusoids was induced by abnormal development of nervous system of anencephalic fetus which was also found in present study. ${ }^{(11)}$

The study conducted on accelerated maturation of adrenal medulla in 50 anencephalic fetuses \& 50 nonanencephalic fetuses. The cells of adrenal medulla showed progressive maturation larger cells with increased cytoplasm $\&$ positive chromaffin reaction. Each anencephalic fetus was compared with control which showed that $70 \%$ of adrenal medulla of anencephalic fetus was more matured, 26\% maturation was equal, 4\% was less mature (p less than 0.001). The explanation for accelerated maturation of adrenal medulla in anencephalic fetus was not known. ${ }^{(12)}$

A study was conducted on ureter structure in anencephalic fetuses. 14 ureters from 7 anencephalic fetuses \& 16 ureters from 8 human fetuses without congenital anomalies age of 16 to 27 weeks. The samples were stained with Masson trichrome to quantify the smooth muscle, ureteral lumen area, thickness \& diameter. The samples were also stained with Weigert Resorcin (elastic fibers) \& Picro Sirius Red with polarization to study the collagen fibers type3. There were no difference in elastic fibers \& total collagen fibers in normal \& anencephalic fetuses. The ureteral lumen area, diameter $\&$ thickness were significantly smaller in anencephalic fetuses. ${ }^{(13)}$

A study on a unique case of Eosinophilic Pancreatitis \& anencephaly in the fetuses of Type 1 diabetic mother. A female fetus of 34 weeks were examined for any gross abnormalities; no abnormalities were identified, pancreas was normal anatomically with no identifiable lesions on routine histology, no hypertrophy \& hyperplasia, pancreatic islets of Langerhans with prominent septal, peri-insular \& islet infiltration with relative sparing of exocrine pancreas was noted. ${ }^{(14)}$

Urinary tract: Horseshoe kidney (0-2\%), hydronephrosis (1-16\%), polycystic or dysplastic kidneys (1-3\%), and unilateral or bilateral renal agenesis $(0-1 \%)$ are associated with anencephaly. ${ }^{(7)}$

According to Kalaycioglu, there was no significant difference in kidneys between normal \& anencephalic fetuses.

GIT: Abnormal development of some hepatocytes \& hepatic sinusoids was induced by abnormal development of nervous system of anencephalic fetuses. ${ }^{(11)}$

Thyroid gland: massive folliculogenesis \& gradual accumulation of colloid in initial stages \& gradual increase in epithelium/colloid ratio \& decrease in size of follicles in later stages was found. ${ }^{(16)}$

The adrenal glands of 12 anencephalic fetuses and 17 normal fetuses of 11 to 21 weeks' gestation were examined histometrically. The volume of the adrenal gland occupied by the fetal zone in the anencephalic fetuses was $57.5 \%$ compared with $76.5 \%$ in normal fetuses. The fetal zone in anencephaly showed involution in all specimens. Which suggests that this involution begins well before 20 weeks' gestation.

Histologically, it was observed that suprarenal gland has a superficial narrow zone of darkly stained cells underneath the capsule, which was the permanent cortex and a deeper lighter zone called the fetal cortex. The changes were seen in thickness of capsule, medulla and the layers of the cortex and these layers were compared with the anencephalic suprarenal gland. The study will establish the micro development of suprarenal gland inhuman fetuses in North-West Indian population. The arrangement of cells in the permanent cortex changed from the discrete cells and clusters to wellformed glomerulus like structure with increasing gestational period. Fasciculoreticular zone of the fetal cortex decreased in thickness as gestation advanced. The cells were arranged in columns extending deeper into the cortex toward medulla. Sinusoidal vessels increased in number and were $34 \mu \mathrm{m}$ wide at $11-15$ weeks and decreased to $15 \mu \mathrm{m}$ at $>25$ weeks gestation. In the medulla, the ganglionic cells were 3-4/field initially which increased to 25-30/field in later gestation period. Few cells showed vacuolization at 11-15 weeks and there was presence of fibrous zone in the medulla consisting of collagen fibers with fibroblasts at $>15-20$ weeks suggesting early degenerative changes whereas in anencephalic fetuses the medulla was observed to be bulkier as compared to permanent cortex. The fetal cortex was observed till 20 weeks of gestation but after 20 weeks fetal cortex diminished. ${ }^{(17)}$

The intake of $4 \mathrm{mg}$ per day of folic acid intake is recommended in mothers with history of neural tube defect. ${ }^{(3,18)}$ 


\section{Conclusion:-}

Incidence of anencephaly is reported to be 1:1000 to 1:20000. In the present study the incidence of anencephaly in Victoria and Vanivilas hospital was 1.04 in 1000 births.

Present study concludes that since there is a chance of occurrence of anencephaly, $4 \mathrm{mg}$ of folic acid should be taken before 6 months of conceiving \& entire pregnancy.

Maternal factors, like age, alcohol consumption, smoking, febrile illness, consumption of certain drugs and chemicals, family history, season of birth, environmental factors, are risk factors of conceiving an anencephalic child and its associated anomalies; hence these factors should be avoided

Consanguineous marriages could be avoided and they could be told about the risks of the same in successive generations too.

All pregnant mothers have to go in for triple marker tests. (beta HCG, alpha fetoprotein and estradiol)

Amniocentesis could be made compulsory for mothers with a history of an anencephalic child. The mother has to be counseled regarding the risks of another such fetus. The family has to be told about pedigree charts, incidence and occurrence of anencephaly in the population.

They should be told about the importance of consuming folic acid before and during pregnancy.

Majority of organs were normal anatomically \& histologically, hence anencephalic fetal organs can be transplanted.

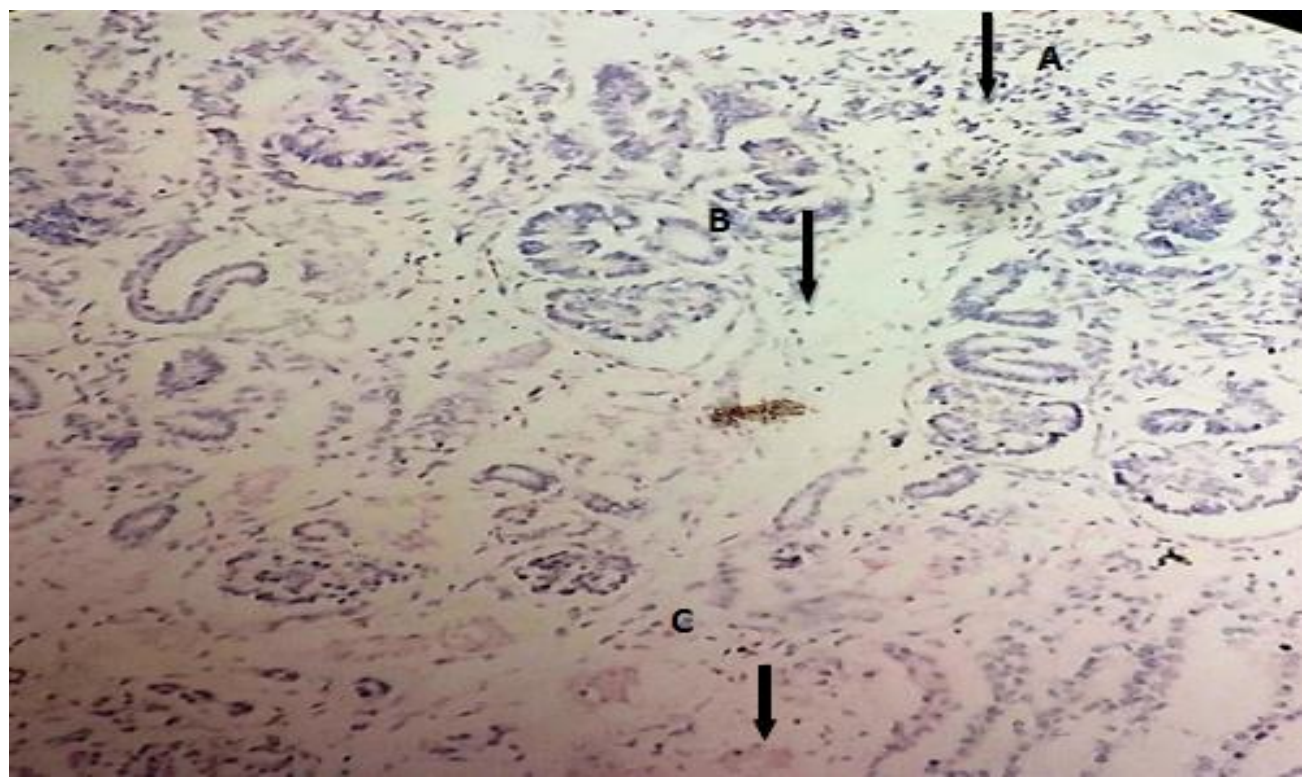

Figure $1 \mathrm{~A}$ :- Photomicrograph of Kidney, stained with H\&E, x10 magnification; A=ill formed nephrogenic zone, $\mathrm{B}=$ illformed glomeruli , $\mathrm{C}=$ renal tubules 


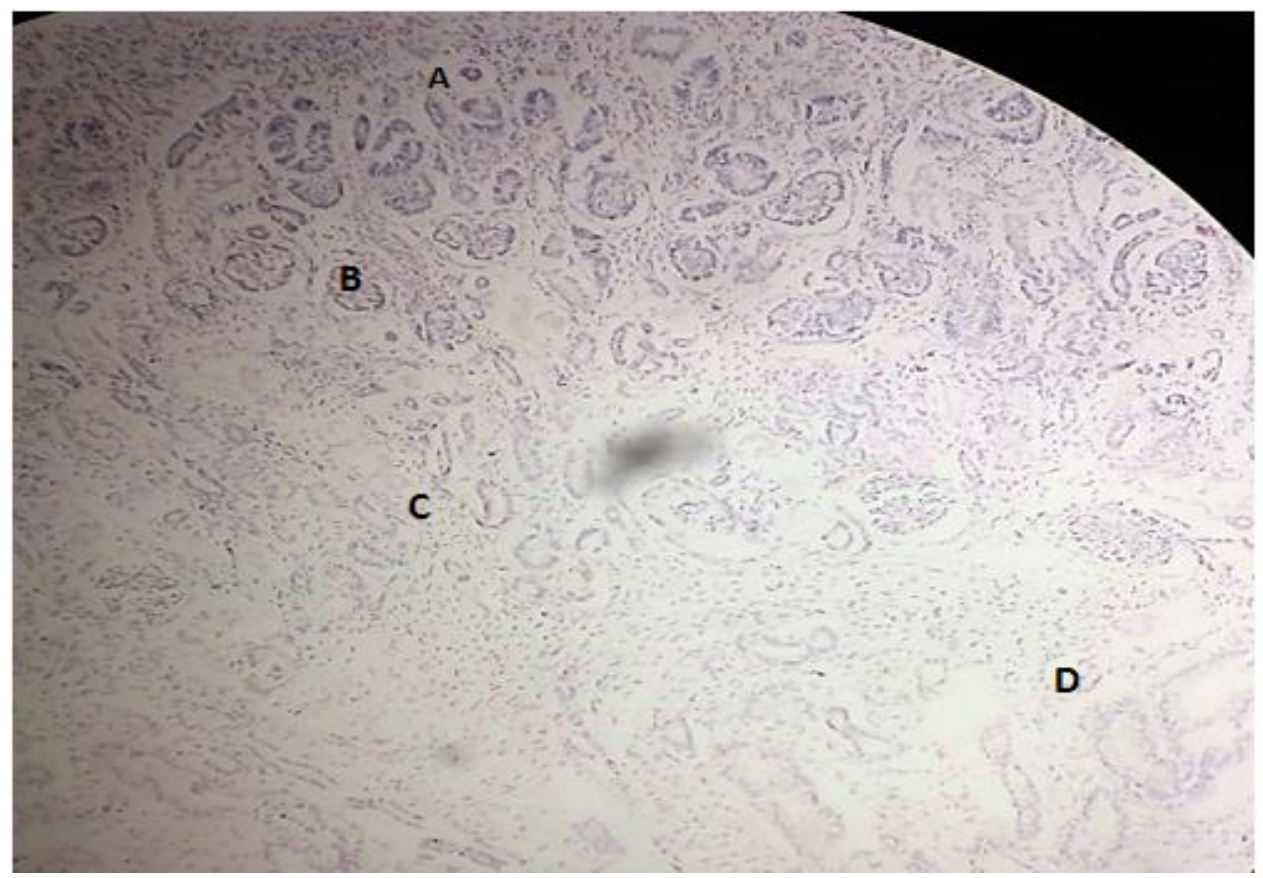

Figure 1 B :- Photomicrograph of Kidney, stained with H\&E, x10 magnification; A=ill formed nephrogenic zone, $\mathrm{B}=$ ill formed glomeruli , $\mathrm{C}=$ renal tubules , $\mathrm{D}$-convoluted tubules.

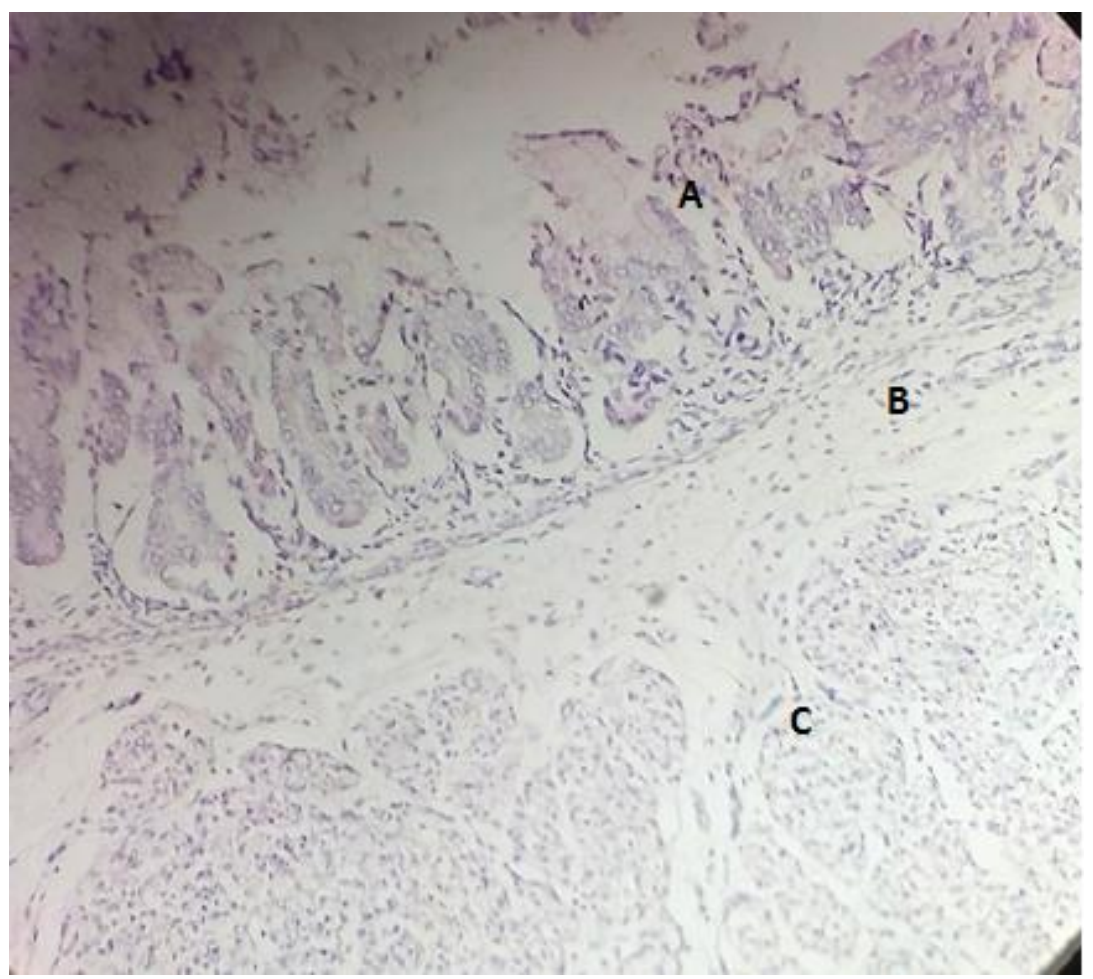

Figure 2:- Photomicrograph of stomach, stained with H\&E, x10 magnification; A-Mucosa, B-Submucosa, CMuscularis Externa. 


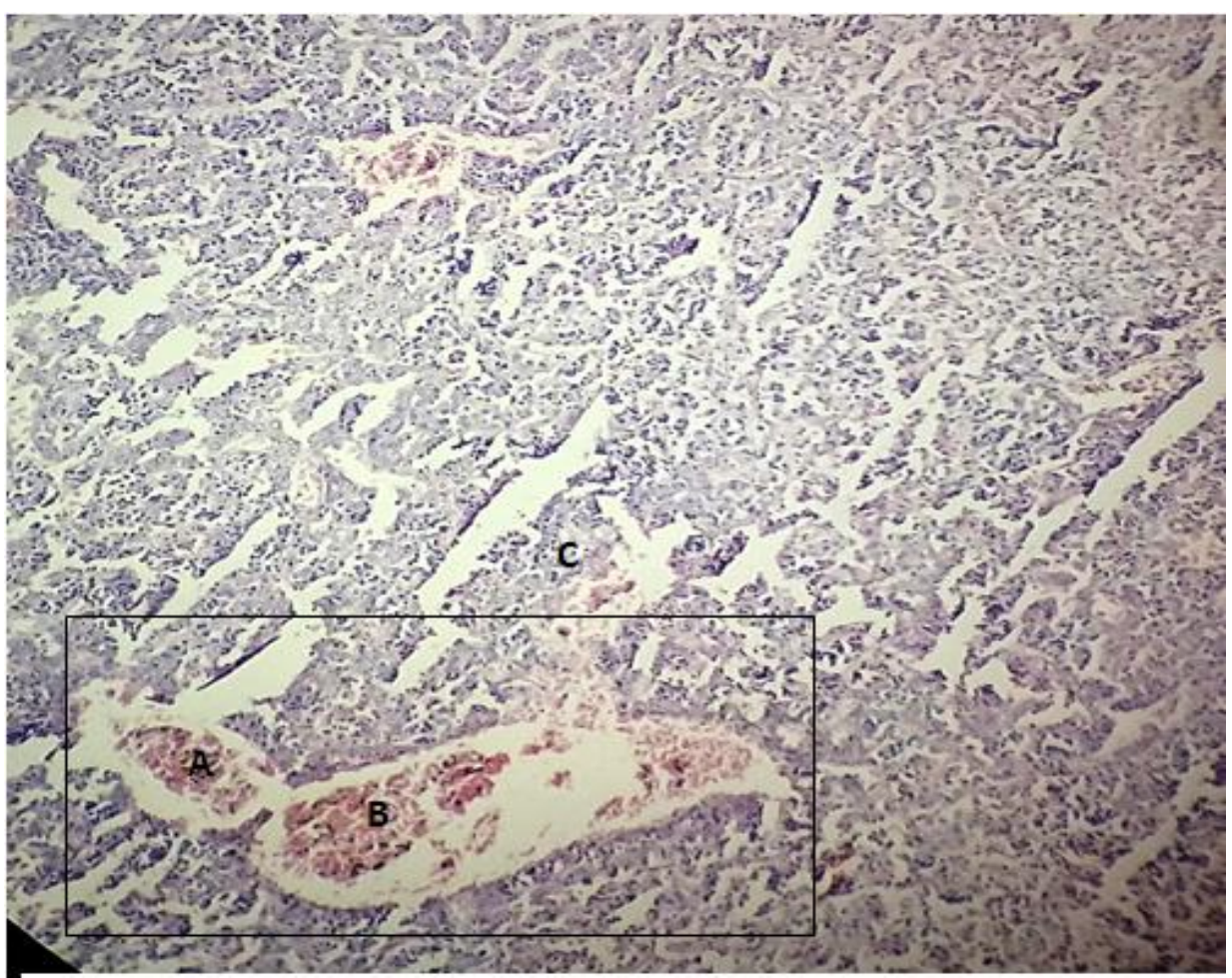

Figure 3:- Photomicrograph of Liver, stained with H\&E, x40 magnification; A-Branches of hepatic artery, B- portal vein, C-Hepatocytes, , C-ill formed portal triad(see insert).

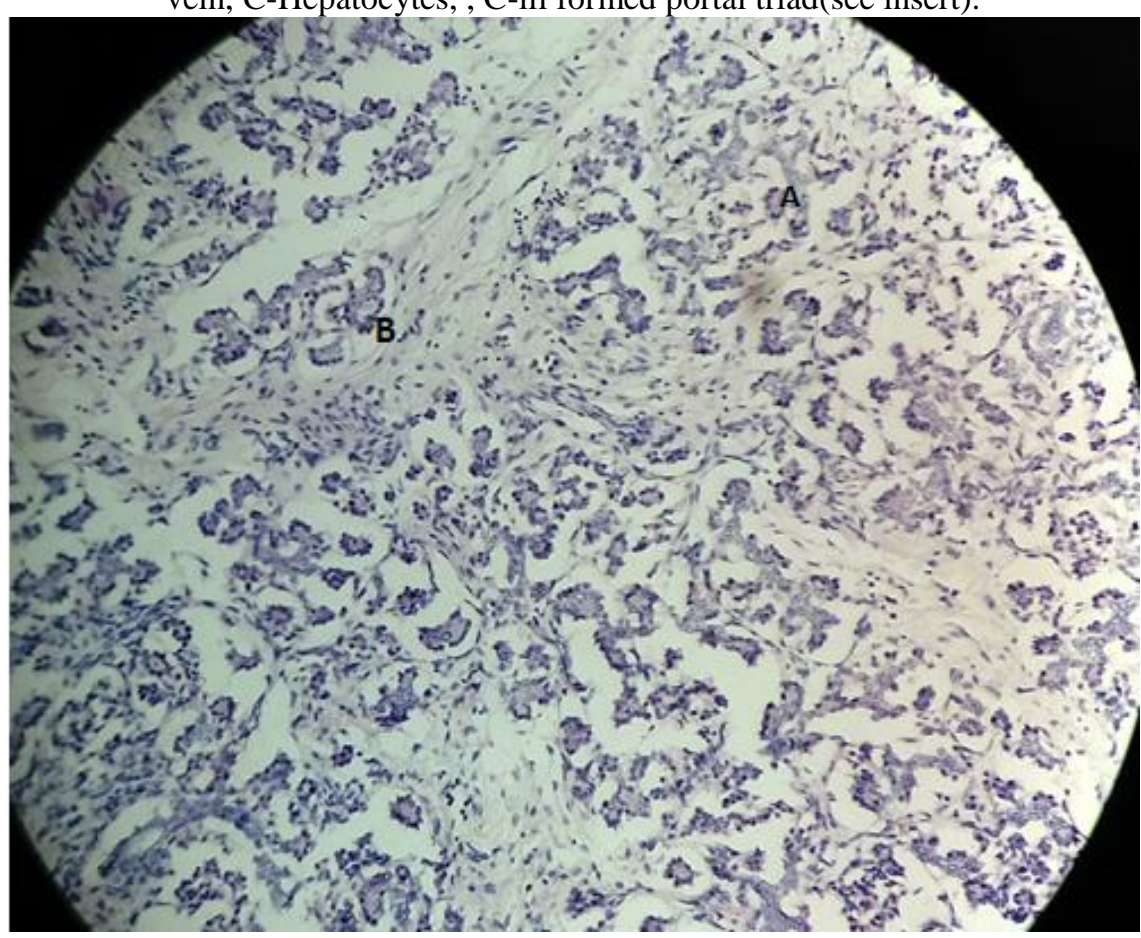

Figure 4:- Photomicrograph of Pancreas, stained with H\&E, x20 magnification; A-serous glands, B- trabeculae( absence of islets of langerhans). 


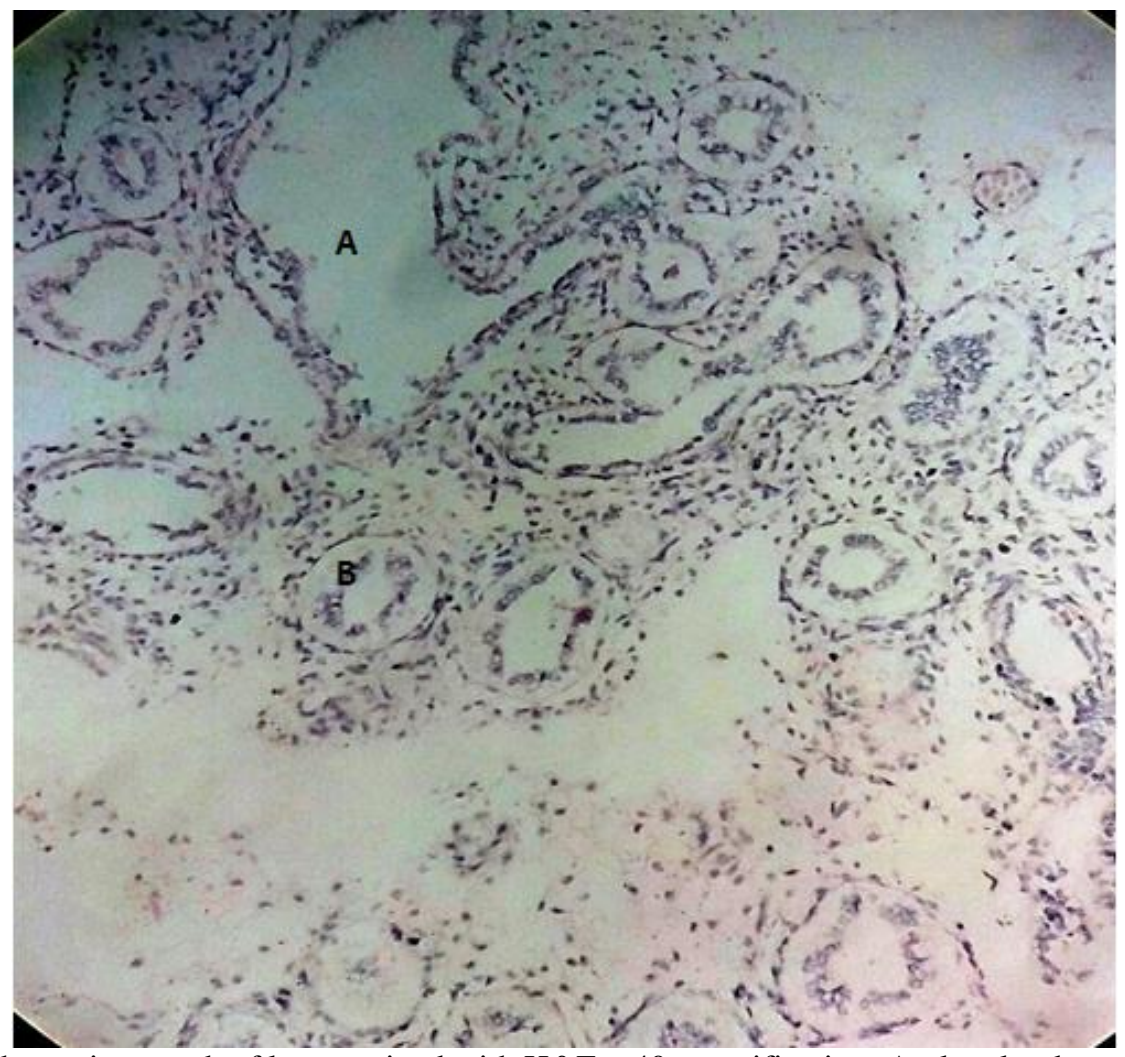

Figure 5A:- Photomicrograph of lung, stained with H\&E, x40 magnification; A-alveolar ducts, B- respiratory bronchioles (alveoli not yet developed).

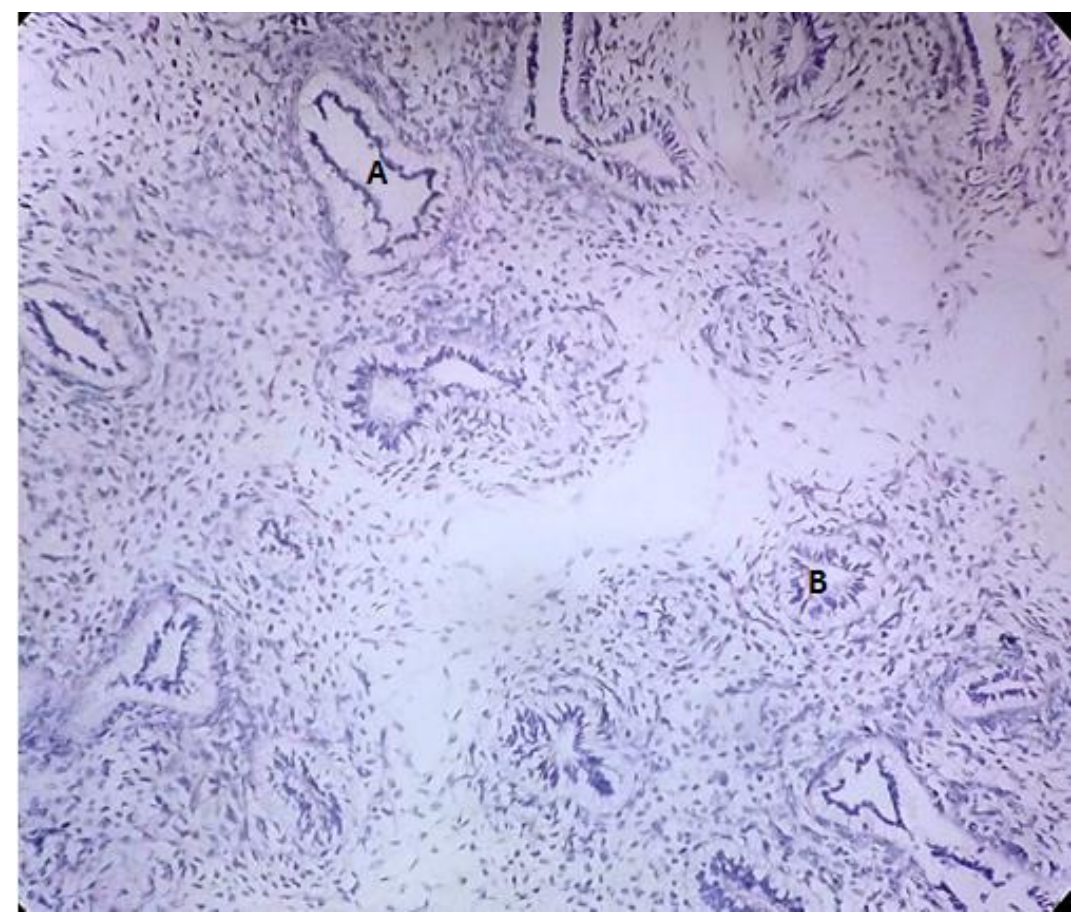

Figure 5 B:- Photomicrograph of lung, stained with H\&E, x20 magnification; A-alveolar ducts, B- respiratory bronchioles (alveoli not yet developed). 


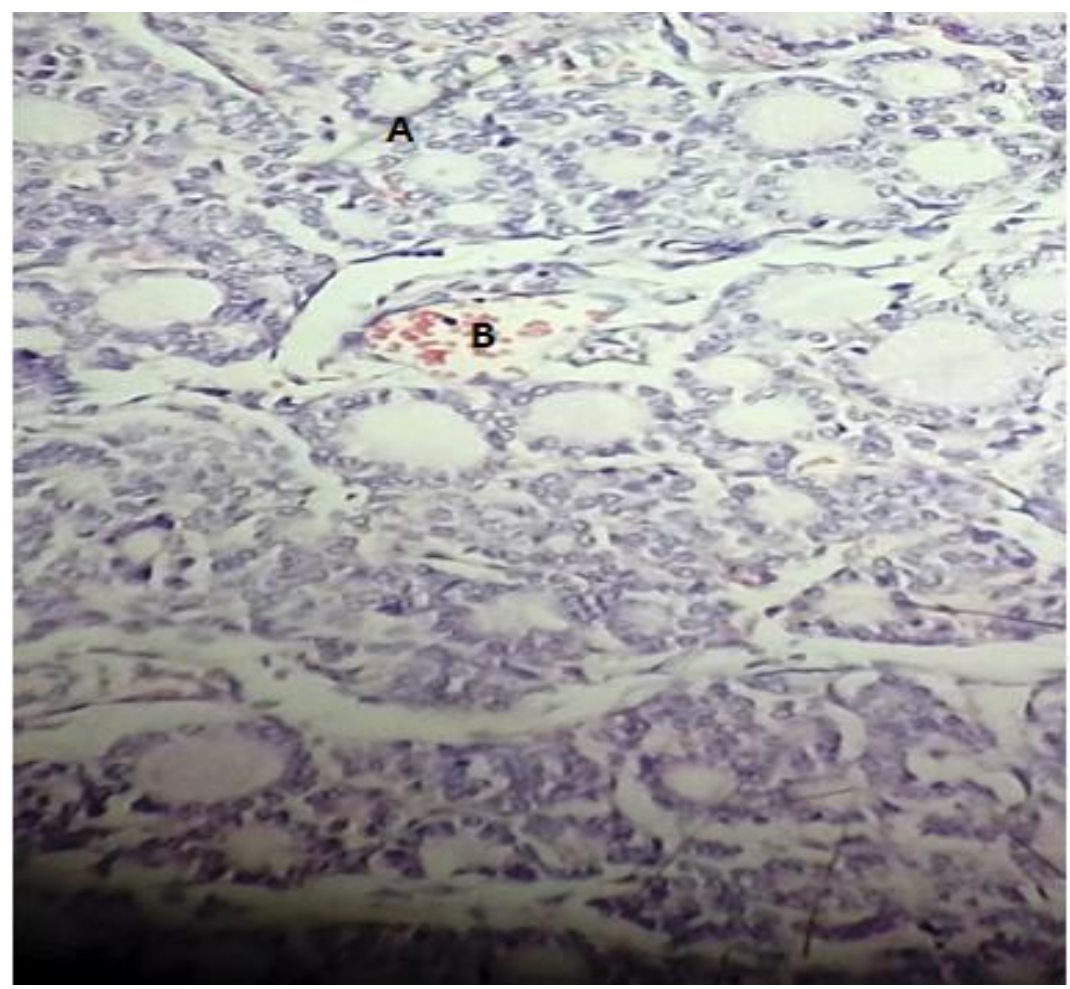

Figure 6:- Photomicrograph of thyroid gland, stained with H\&E, x40 magnification; A-ill formed thyroid follicles, B- blood vessel.

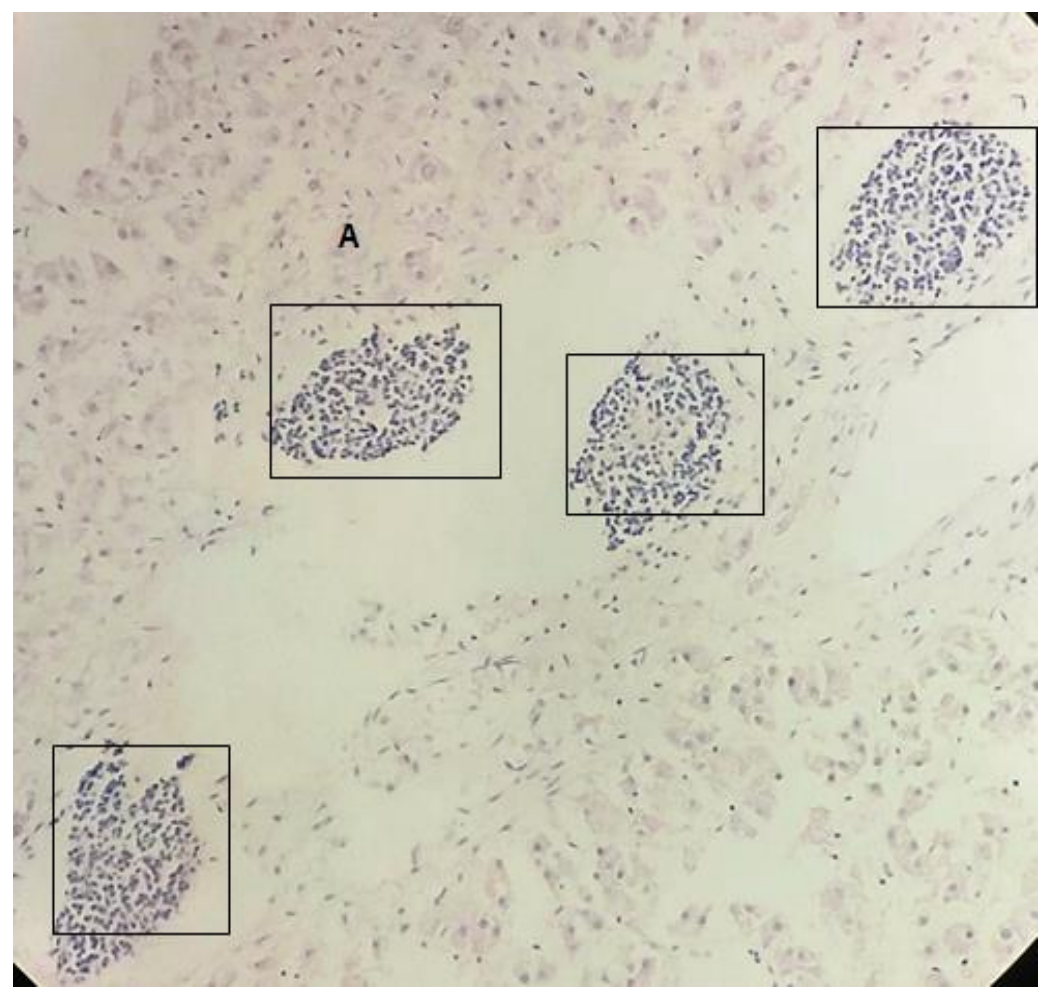

Figure 7:-Photomicrograph of suprarenal gland, stained with H\&E, x10 magnification; A- rosettes cell tumor neuroblastoma(see insert) 


\section{References:-}

1. Langman Text book of embroyology: In: Medical Embryology, Indian edition, scientific book agency, Calcutta, 1966:75,257,275.

2. Arey L.B: In: Development anatomy- A textbook \& laboratory manual of embrylogy, $7^{\text {th }}$ edition, W.B. Saunders Co, Philadelphia \& London, Toppan Co. Ltd, Tokya, 1966.

3. Lisa Moore, Anencephaly, Journal of Diagnostic Medical Sonography 2010, 26 (6)286-289

4. Moore KL., Persaud TVN: In: The Developing Brain-Clinically oriented Embryology. ${ }^{\text {th }}$ edition, W.B. Saunders Co, Philadelphia. 1999:419,463.

5. Chan C, Hsieh WS, Peng SS: Klippel-F eil syndrome plus atretic meningpcele in one identical twin and anencephaly in the other. J Formos Med Assoc 2003: 102 (7): 506-509.

6. Priya Ranganath, Sayee Rajangam, Perinatology- Journal of perinatal and neonatal care vol 9 (1):43-47, 2007

7. Ozturk AH, Kurtoglu Z., Tunncel M, Uluutku H, Aktekin M, Comparison of thickness of myocardial fibres of anencephalic and normal human fetuses. Turk J Pediatr 2002:44 (4):330-333.

8. $\quad$ N Engl J Med 1990; 322:669-674 March 8, 1990 DOI: 10:10056/NEJM 199003083221006.

9. Dambska M, Taraszewska A, Czwalinska T: A case of Pseudo-aprosencephaly. Folia neuropathol 2002:40 (3):161-164.

10. AJ Patowary :the fourth incision -few modifications in autopsy incisions, $\mathrm{J}$ Indian acad forensic med $32(3)$ pg 234-238 ISSN 0971-0973

11. L IU Jiang -Zhou Wen -Jun The Histological observation of liver of Anencephaly fetus Journal of Hubei vocational technical college 2006-03 XGZJ20060302

12. AB Namnoum ;GM Hutchins Accelerated maturation of the adrenal medulla in anencephaly Elesvier BV 1990;10(6);895-900)

13. Suelen Costa ,Joao P.M ,Waldemar s Study of ureter structure in Anencephalic fetuses IBJU 2013;39;512-519)

14. Eliza R George,Shirali S Patel ,Priyanka Sen A unique case of Eosinophilic Pancreatitis \& anencepha ly in the fetuses of Type 1 diabetic mother Gastroenterology research 2011;4;4;174-176)

15. Kalaycioglu A, Ucuncu Y, Altunkaynak BZ, Altunkaynak ME, Gundogdu C, Keles ON, Unal B, Kaplan S. Stereological evaluation of kidneys of anencephalic \& normal foetuses. Renal Failure, 2013; 35 (1): $110-117$.

16. Bocian-Sobkowska J, Wozniak W, Malendowicz LK. Morphometric studies on the development of human thyroid gland in late fetal life. Histol Histopathol, 1997. 12: 79-84

17. Shantaram K, Sharma A, Sharma M, Comparative microanatomy of suprarenal gland of anencephalic and normal fetuses of different gestational age groups Journal of the Anatomical Society of India February 2017;65(2) .

18. Potters pediatric pathology volume $1 \&$ volume 2 second edition

19. Gupta P, Nain P \& Singh J. Anencephaly:A Neural tube defects -A review, American journal of pharmtech research , 2016; 2(3).t). 